\title{
A TITAN step forward: apalutamide for metastatic castration- sensitive prostate cancer
}

\author{
Daniel Hyuck-Min Kwon ${ }^{1,2}$, Terence Friedlander ${ }^{1,2}$ \\ ${ }^{1}$ Department of Medicine, Division of Hematology and Oncology, ${ }^{2}$ The Helen Diller Family Comprehensive Cancer Center, University of California \\ San Francisco, San Francisco, CA, USA \\ Correspondence to: Terence Friedlander, MD. 995 Potrero Avenue, Building 80, Ward 84, San Francisco, CA 94110, USA. \\ Email: terence.friedlander@ucsf.edu. \\ Provenance: This is an article commissioned by the Section Editor Weijun Jiang (Nanjing Normal University, Department of Reproductive and \\ Genetics, Institute of Laboratory Medicine, Jinling Hospital, Nanjing University School of Medicine, Nanjing, China). \\ Comment on: Chi KN, Agarwal N, Bjartell A, et al. Apalutamide for Metastatic, Castration-Sensitive Prostate Cancer. N Engl J Med 2019;381:13-24.
}

Submitted Aug 10, 2019. Accepted for publication Aug 30, 2019.

doi: $10.21037 /$ atm.2019.09.21

View this article at: http://dx.doi.org/10.21037/atm.2019.09.21

Metastatic prostate cancer, which presents as either de novo (4-5\% of cases) or as a recurrence following definitive therapy for localized disease, has historically been treated with androgen deprivation therapy (ADT) alone. Although $90 \%$ of men initially respond to ADT, almost all eventually become castration-resistant and develop progression of their disease. Over the past several years, several landmark randomized clinical trials have led to the use of docetaxel, a taxane chemotherapy administered intravenously every 3 weeks for 6 cycles, or abiraterone, an orally administered inhibitor of CYP17A1 given together with a low-dose glucocorticoid, in combination with ADT as standard of care among men with metastatic castration-sensitive prostate cancer (mCSPC) (1-4). The median overall survival with these therapies is upwards of 53 months, depending on the disease stage, extent, and burden of the study population.

Apalutamide, an oral androgen receptor (AR) antagonist significantly more potent than first-generation antiandrogens such as bicalutamide, prevents AR nuclear translocation, DNA binding, and transcription of downstream elements (5). In 2018, the SPARTAN trial demonstrated an improvement in median metastasisfree survival among men with high-risk non-metastatic castration-resistant prostate cancer compared to placebo (40.5 vs. 16.2 months) with no detriment to healthrelated quality of life (HRQoL) $(6,7)$. Enzalutamide and darolutamide, both in the same class of next-generation anti-androgens, have also demonstrated clinical benefit in men with high-risk non-metastatic castration-resistant prostate cancer $(8,9)$.

At this year's American Society of Clinical Oncology Annual Meeting and in the May issue of the New England Fournal of Medicine, Chi et al., reported the results of a planned interim analysis of the TITAN (Targeted Investigational Treatment Analysis of Novel Anti-androgen) trial, a randomized, double-blind, placebo-controlled, international study in which apalutamide administered at a dose of 240 mg per day in combination with ADT was associated with an improvement in overall survival compared to ADT alone among men with recently diagnosed mCSPC $(82.4 \%$ alive at 24 months $v s .73 .5 \%$, respectively, hazard ratio for death, $0.67)(10)$. The trial was designed by the sponsor, Janssen Research and Development, with investigator input, and randomized 1,052 men to apalutamide or placebo. The experimental arm reported more rashes, fatigue, fractures, and hypothyroidism; however, rates of serious adverse events were similar in both groups. Patient-reported outcomes using FACT-P were also reported, with no significant difference in HRQoL. An overall survival benefit was maintained across all reported subgroups, including those who had received prior docetaxel (11\% of patients) and those with high-volume disease ( $63 \%$ of patients), defined as presence of visceral metastases and at least one bone lesion, or at least four bone lesions with at least one outside the axial skeleton.

What can we learn from the TITAN study? It seems clear that apalutamide is active in $\mathrm{MCSPC}$, and given the robust results observed it, we now can add apalutamide 
Table 1 Comparison of systemic therapies shown to improve overall survival when added to ADT among men with mCSPC

\begin{tabular}{|c|c|c|c|c|}
\hline Characteristic & Docetaxel & Abiraterone & Apalutamide & Enzalutamide \\
\hline Study & STAMPEDE (2) & STAMPEDE (4) & & \\
\hline Population & $\begin{array}{l}\text { High-volume } \\
\text { metastatic }^{\dagger \neq}\end{array}$ & Metastatic & Metastatic & Metastatic \\
\hline Duration of treatment & 18 weeks & $\begin{array}{l}\text { Indefinite, median } \\
33 \text { mo }\end{array}$ & $\begin{array}{l}\text { Indefinite, median } \\
>36 \text { mo }\end{array}$ & Indefinite, median $>48$ mo \\
\hline $\begin{array}{l}\text { Clinically important } \\
\text { toxicities }\end{array}$ & $\begin{array}{l}\text { Febrile neutropenia, } \\
\text { alopecia, peripheral } \\
\text { neuropathy }\end{array}$ & $\begin{array}{l}\text { Arrhythmias, } \\
\text { hypertension, } \\
\text { hypokalemia }\end{array}$ & $\begin{array}{l}\text { Fatigue, fractures, } \\
\text { hypothyroidism, rash }\end{array}$ & $\begin{array}{l}\text { Cognitive dysfunction, fatigue, } \\
\text { seizures, syncope }\end{array}$ \\
\hline Corticosteroids & Yes & Yes & No & No \\
\hline HRQoL & Improved $^{\S}$ & Improved (13) & Preserved & To be reported \\
\hline
\end{tabular}

${ }^{\dagger}$, STAMPEDE included patients with not only metastatic disease, but also locally advanced disease, high-risk non-metastatic disease, and highrisk relapse after primary treatment; ${ }^{\ddagger}$, high volume per CHAARTED presence of visceral metastases and/or at least four bone lesions with at least one lesion outside of the vertebral column and/or pelvis; ${ }^{\S}$, HRQoL was worse at 3 months, but better at 12 months (15); ", assumes full dose of $1,000 \mathrm{mg}$ branded abiraterone daily. Abiraterone in generic form has been approved by the Food and Drug Administration, and $250 \mathrm{mg}$ with a low-fat meal has been shown to be non-inferior to full dose in metastatic castration-resistant prostate cancer based on PSA response in a small study (16). ADT, androgen deprivation therapy; mCSPC, metastatic castration-sensitive prostate cancer.

to the armamentarium of life-prolonging therapies for men with mCSPC. However, we again find ourselves in a privileged dilemma of choosing among multiple effective drugs: docetaxel, abiraterone, apalutamide, enzalutamide [given the positive results of the simultaneously published ENZAMET trial (11)], and likely darolutamide. All of the phase III trials investigating these agents in mCSPC have shown similar hazard ratios for death, and except for abiraterone and docetaxel, none have been compared head-to-head, meaning there is no direct evidence that one is superior to another. Indeed, the only head-to-head, randomized, prospective comparison was reported in the multi-arm, multi-stage STAMPEDE trial, in which no difference in overall survival or other important outcomes such as symptomatic skeletal events was found when comparing men with $\mathrm{mCSPC}$ treated with abiraterone to those treated with docetaxel (12). Therefore, selection among these drugs should be based on patient-centered and broader economic considerations, i.e., duration of treatment (a relatively short 18 weeks for docetaxel versus indefinitely for the hormonal agents), toxicity profiles, and cost-effectiveness based on quality-adjusted life years. The first discriminating branch point should be whether to administer chemotherapy versus further androgen blockade based on disease volume and patient comorbidities and functional status, and then by toxicity and cost (Table 1) (1-4,10,11,13-16).

Many questions surrounding the optimal treatment of men with mCSPC remain. Further intensification of therapy by adding either chemotherapy or a second next-generation anti-androgen to the backbone of ADT + anti-androgen is being studied, though we know that adding docetaxel to enzalutamide + ADT did not improve survival in an interim analysis of ENZAMET (11). Similarly, the combination of enzalutamide with abiraterone/prednisone was no more effective than enzalutamide alone in men with mCRPC (17), and it remains to be seen if combining these classes of agents in the mCSPC setting will have activity. Further studies (PEACE-1, ARCHES, and ARASENS) will better clarify the role of these novel agents in the mCSPC setting (Table 2). How localized treatment of the prostate tumor, e.g., low-dose radiotherapy to the primary tumor for men with low-volume, newly diagnosed mCSPC in STAMPEDE (18), or localized radiotherapy for oligometastases will fit into the current paradigm remains unclear. And of course, optimal sequencing of these therapies remains unknown. In terms of patient selection, investigation of biomarkers such as ARv7 splice variants, circulating tumor cells and cell-free DNA, gene expression profiles, and mutations in DNA damage repair genes in the 
Table 2 Comparison of ongoing clinical trials investigating systemic therapies for men with mCSPC

\begin{tabular}{|c|c|c|c|c|c|c|c|c|}
\hline $\begin{array}{l}\text { Study (NCT } \\
\text { number) }\end{array}$ & $\mathrm{N}$ & $\begin{array}{l}\text { Primary } \\
\text { completion } \\
\text { date }\end{array}$ & $\begin{array}{l}\text { Experimental arm } \\
\text { (with ADT) }\end{array}$ & $\begin{array}{l}\text { Control arm } \\
\text { (with ADT) }\end{array}$ & Docetaxel use & $\begin{array}{l}\text { Stratified by } \\
\text { docetaxel use }\end{array}$ & $\begin{array}{l}\text { Primary } \\
\text { endpoint }\end{array}$ & $\begin{array}{l}\text { Hazard } \\
\text { ratio for } \\
\text { endpoint }\end{array}$ \\
\hline $\begin{array}{l}\text { PEACE } 1 \\
(01957436)\end{array}$ & 1,173 & 2019 & $\begin{array}{l}\text { Docetaxel with } \\
\text { abiraterone, RT, or } \\
\text { both }\end{array}$ & Docetaxel & Required & NA & OS/PFS & NA \\
\hline $\begin{array}{l}\text { ENZAMET } \\
(02446405)\end{array}$ & 1,125 & 2020 & Enzalutamide & $\begin{array}{l}\text { Anti- } \\
\text { androgen }\end{array}$ & $\begin{array}{l}\text { Up to } 6 \text { cycles } \\
\text { allowed }\end{array}$ & Yes & OS & 0.67 \\
\hline $\begin{array}{l}\text { TITAN } \\
(02489318)\end{array}$ & 1,052 & 2020 & Apalutamide & Placebo & $\begin{array}{l}\text { Up to } 6 \text { cycles } \\
\text { allowed }\end{array}$ & Yes & OS/rPFS & $0.67 / 0.48$ \\
\hline $\begin{array}{l}\text { ARASENS } \\
(02799602)\end{array}$ & 1,303 & 2022 & $\begin{array}{l}\text { Darolutamide + } \\
\text { docetaxel }\end{array}$ & Docetaxel & Required & NA & OS & NA \\
\hline $\begin{array}{l}\text { SWOG } 1216 \\
\text { (01809691) }\end{array}$ & 1,313 & 2022 & Orteronel & Bicalutamide & Prohibited & NA & OS & NA \\
\hline
\end{tabular}

mCSPC, metastatic castration-sensitive prostate cancer; ADT, androgen deprivation therapy; rPFS, radiographic progression-free survival; OS, overall survival.

prediction of response to these therapies, as well as frontline PARP inhibitors and platinum-based chemotherapy, is underway. Additionally, the increasing use of highly sensitive PSMA-PET scans will upstage many patients deemed to have non-metastatic disease by conventional imaging. It is unknown whether outcomes for these upstaged patients treated with novel hormone therapies and/or chemotherapy differ from those with objective metastases by conventional scans, and investigators should consider the risks of overtreatment for these patients in future studies.

As the armamentarium of both localized and systemic therapies for men with $\mathrm{mCSPC}$ continues to expand in this exciting, evolving landscape, issues of equitable access to treatment, and of cost-effective, high-value care must be addressed. For example, the cost of next-generation hormone therapies can range from several thousands of dollars per month for generic abiraterone acetate in the United States, to up to $\$ 12,000$ per month for branded enzalutamide (Xtandi) and apalutamide (Erleada). And with multiple studies demonstrating survival benefits associated with earlier treatment, a number of questions arise as patients live longer. Is the increased risk of longer-term toxicity worth the gain in survival? How can we support our patients to maintain HRQoL? How can our health care system pay for increasingly expensive medications?

It is crucial to effectively deliver and further investigate individual and system-level interventions that mitigate factors that decrease HRQoL, such as the side effects of ADT and other systemic therapies, urinary and sexual dysfunction, skeletal related events, and financial toxicity. Multidisciplinary teams that address the wide spectrum of symptoms suffered by patients must be formed. Broadening the definition of prostate cancer survivorship to include long-term survivors of metastatic prostate cancer, increasing the use of patient reported outcomes (PROs), and focusing on HRQoL are imperative in addressing the medical and psychologic needs of this growing population of survivors, and should be taken into account as more life-prolonging therapies become available to men with mCSPC.

\section{Acknowledgments}

None.

\section{Footnote}

Conflicts of Interest: $T$ Friedlander participated in an advisory board for Janssen. The other author has no conflicts of 
interest to declare.

Ethical Statement: The authors are accountable for all aspects of the work in ensuring that questions related to the accuracy or integrity of any part of the work are appropriately investigated and resolved.

\section{References}

1. Sweeney CJ, Chen YH, Carducci M, et al. Chemohormonal Therapy in Metastatic HormoneSensitive Prostate Cancer. N Engl J Med 2015;373:737-46.

2. James ND, Sydes MR, Clarke NW, et al. Addition of docetaxel, zoledronic acid, or both to first-line longterm hormone therapy in prostate cancer (STAMPEDE): survival results from an adaptive, multiarm, multistage, platform randomised controlled trial. Lancet 2016;387:1163-77.

3. Fizazi K, Tran N, Fein L, et al. Abiraterone plus Prednisone in Metastatic, Castration-Sensitive Prostate Cancer. N Engl J Med 2017;377:352-60.

4. James ND, de Bono JS, Spears MR, et al. Abiraterone for Prostate Cancer Not Previously Treated with Hormone Therapy. N Engl J Med 2017;377:338-51.

5. Smith MR, Antonarakis ES, Ryan CJ, et al. Phase 2 Study of the Safety and Antitumor Activity of Apalutamide (ARN-509), a Potent Androgen Receptor Antagonist, in the High-risk Nonmetastatic Castration-resistant Prostate Cancer Cohort. Eur Urol 2016;70:963-70.

6. Smith MR, Saad F, Chowdhury S, et al. Apalutamide Treatment and Metastasis-free Survival in Prostate Cancer. N Engl J Med 2018;378:1408-18.

7. Saad F, Cella D, Basch E, et al. Effect of apalutamide on health-related quality of life in patients with nonmetastatic castration-resistant prostate cancer: an analysis of the SPARTAN randomised, placebo-controlled, phase 3 trial. Lancet Oncol 2018;19:1404-16.

8. Hussain M, Fizazi K, Saad F, et al. Enzalutamide in Men with Nonmetastatic, Castration-Resistant Prostate Cancer. N Engl J Med 2018;378:2465-74.

9. Fizazi K, Shore N, Tammela TL, et al. Darolutamide in

Cite this article as: Kwon DH, Friedlander T. A TITAN step forward: apalutamide for metastatic castration-sensitive prostate cancer. Ann Transl Med 2019;7(Suppl 8):S364. doi: 10.21037/ atm.2019.09.21
Nonmetastatic, Castration-Resistant Prostate Cancer. N Engl J Med 2019;380:1235-46.

10. Chi KN, Agarwal N, Biartell A, et al. Apalutamide for Metastatic, Castration-Sensitive Prostate Cancer. N Engl J Med 2019;381:13-24.

11. Davis ID, Martin AJ, Sockler MR, et al. Enzalutamide with Standard First-Line Therapy in Metastatic Prostate Cancer. N Engl J Med 2019;381:121-31.

12. Sydes MR, Spears MR, Mason MD, et al. Adding abiraterone or docetaxel to long-term hormone therapy for prostate cancer: directly randomised data from the STAMPEDE multi-arm, multi-stage platform protocol. Ann Oncol 2018;29:1235-48.

13. Chi KN, Protheroe A, Rodriguez-Antolín A, et al. Patient-reported outcomes following abiraterone acetate plus prednisone added to androgen deprivation therapy in patients with newly diagnosed metastatic castrationnaive prostate cancer (LATITUDE): an international, randomised phase 3 trial. Lancet Oncol 2018;19:194-206.

14. Sathianathen NJ, Alarid-Escudero F, Kuntz KM, et al. A Cost-effectiveness Analysis of Systemic Therapy for Metastatic Hormone-sensitive Prostate Cancer. Eur Urol Oncol 2019. [Epub ahead of print].

15. Morgans AK, Chen YH, Sweeney CJ, et al. Quality of Life During Treatment With Chemohormonal Therapy: Analysis of E3805 Chemohormonal Androgen Ablation Randomized Trial in Prostate Cancer. J Clin Oncol 2018;36:1088-95.

16. Szmulewitz RZ, Peer CJ, Ibraheem A, et al. Prospective International Randomized Phase II Study of Low-Dose Abiraterone With Food Versus Standard Dose Abiraterone In Castration-Resistant Prostate Cancer. J Clin Oncol 2018;36:1389-95.

17. Morris MJ, Heller G, Bryce, AH, et al. Alliance A031201: A phase III trial of enzalutamide (ENZ) versus enzalutamide, abiraterone, and prednisone (ENZ/AAP) for metastatic castration resistant prostate cancer (mCRPC). J Clin Oncol 2019;37;abstr 5008.

18. Parker CC, James ND, Brawley CD, et al. Radiotherapy to the primary tumour for newly diagnosed, metastatic prostate cancer (STAMPEDE): a randomised controlled phase 3 trial. Lancet 2018;392:2353-66. 